\title{
Uma cultura mutante: 0 chimarrão e seus artefatos analisados sob o viés do design vernacular e do imaginário
}

ARTIGO

\author{
A mutant culture: the chimarrão and its artifacts \\ analyzed under the vernacular design and imaginary
}

Alexandre Vergínio Assunção http://lattes.cnpq.br/1426674469040108

Rafael Klumb Arnoni

http://lattes.cnpq.br/8769816614511557

\section{Luiz Antônio Pereira Machado Júnior \\ http://lattes.cnpq.br/0732401371396501}

\section{Resumo}

O chimarrão sofre ao longo do tempo mudanças, tanto no seu simbolismo quanto na forma dos artefatos necessários à sua utilização. Essas incorporações servem como uma rica fonte de pesquisa ao design vernacular e aos estudos do imaginário. Neste artigo trazemos uma síntese analítica sobre aspectos culturais, imaginários, simbólicos e técnicos do chimarrão através de pesquisa bibliográfica e iconográfica, no âmbito da hermenêutica simbólica - que se define como interpretação compreensiva do sentido das produções e memórias humanas (RICOEUR, 2009; DURAND, 1996), buscando-se contextualizar sua utilização nos dias atuais. As conclusões revelam que os grupos e as segmentações de uso, em um tempo histórico, sempre interpretam e reelaboram aquilo que neste campo lhes é oferecido, transformando esses artefatos em elementos heterogêneos.

\section{Palavras-chave}

Chimarrão. Design Vernacular. Imaginário. Hermenêutica Simbólica. Dinâmica da Cultura.

\section{Abstract}

Chimarrão suffers over time changes, both in its symbolism and in the form of artifacts necessary for its use. These embodiments serve as a rich source of research to vernacular design and imaginary studies. In this article we present an analytical synthesis on cultural, imaginary, symbolic and technical aspects of chimarrão through bibliographical and iconographic research, within the framework of symbolic hermeneutics - defined as a comprehensive interpretation of the meaning of human productions and memories (RICOEUR, 2009; DURAND, 1996), seeking to contextualize its use in the present day. The conclusions show that the groups and the segmentations of use, in a historical time, always interpret and rework what is offered to them in this field, turning these artifacts into heterogeneous elements.

\section{Keywords}

Chimarrão. Vernacular Design. Imaginary.

Symbolic Hermeneutics. Dynamics of Culture.

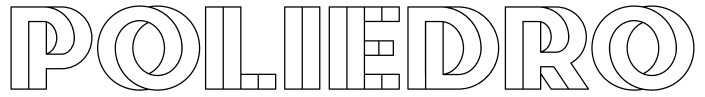




\section{Breves palavras introdutórias}

O que é o chimarrão? Qual a sua história? Quais são os "avios" necessários para tomá-lo? De que materiais são feitos esses artefatos e como o design pode analisá-los técnica e simbolicamente? Estas são algumas das questões deste artigo. Vamos contextualizá-las. O chimarrão - bebida resultante da infusão da erva-mate, depositada em uma cuia ${ }^{[1]} \mathrm{e}$ sugada através de uma bomba - está entre os costumes mais conhecidos da região sul do Brasil e de países como Uruguai e Argentina, tornando-se um ícone representativo destas culturas. Pode ser associado a um modo de vida ligado ao campo - e também à cidade - que está enraizado historicamente nessas regiões, trazendo consigo aspectos que se vinculam à sua tradição, à sua história e à sua identidade, ao imaginário, à história, à memória e à identidade de um grupo social, e que vai modificando os seus "avios" ou artefatos.

Toda "tradição" é uma expressão cultural de um tempo e espaço, constantemente ressignificada, modificada e também "inventada" por seus agentes, para adaptar-se aos novos usos atribuídos por estes (ARÉVALO, 2004, HOBSBAWN,2015). Levando em conta essa afirmação, pode-se assegurar que o chimarrão e seus rituais fazem parte de uma tradição bastante enraizada na Região Platina da América do Sul, incorporada pelos jesuítas no período de colonização ibérica, difundida ao longo do tempo e instituída como uma bebida típica desta região. Essa tradição cultural sofreu, desde sua incorporação à cultura regional, mudanças relacionadas em especial aos seus rituais, simbolismos, portanto, a materialidade de seus artefatos e seu "imaginário". Este imaginário, como escreve Wunenburger (2007), é "um conjunto de produções, mentais ou materializadas em obras, com base em imagens visuais e lingüísticas, formando conjuntos coerentes e dinâmicos, referentes a uma função simbólica no sentido de um ajuste de sentidos próprios e figurados" (p. 11). Por isso, em função de um imaginário simbólico e criador, ao longo do tempo o artefato/chimarrão foi modificando sua forma: agregaram-lhe adornos

[1] A cuia é nomeada de "mate" em países como a Argentina e o Uruguai. Portanto, nesses países, "mate" é tanto o artefato que contém a erva, como a própria infusão que lhe é sorvida.

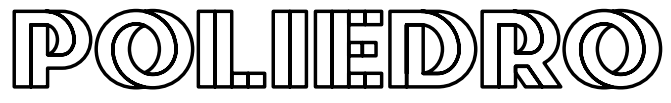


que demonstravam o status de seu possuidor e incorporaram-lhe novas tecnologias em seus materiais (Figura 1). Por fim, foi-lhe atribuído o sentido e o estatuto de um dos representantes da identidade gaúcha.

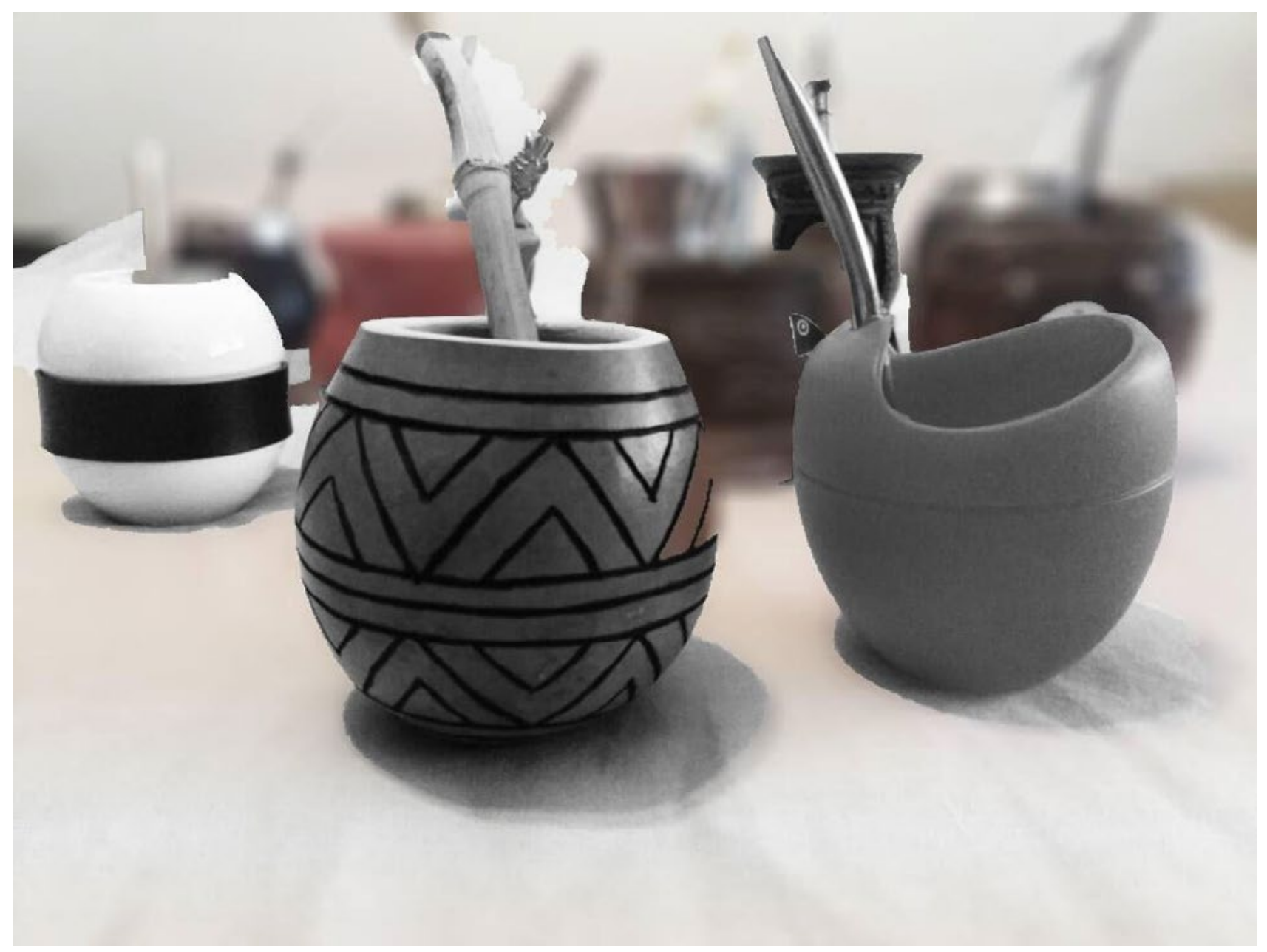

Figura 1 - Da indígena cuia de porongo e bomba taquapi ao silicone e inox atual, entremeadas por produções em madeira, metal e cerâmica, são interesses deste trabalho. Elaborada pelos autores.

Do ponto de vista antropológico, preferimos o termo "artefato" ao invés de objeto, pois se refere especificamente a "um objeto feito pela incidência da ação humana sobre a matéria-prima" (CARDOSO, 2013, p. 47), em contraposição aos objetos naturais ou acidentais. A utilização do termo "vernacular" é empregada aqui para definir aqueles artefatos autênticos da cultura de determinado local, geralmente produzidos à margem do design oficial (FINIZOLA, 2010, p.30). O Design Vernacular, para 
este trabalho, é interpretado como um estudo aproximado de antropologia cultural material - no segmento de uma abordagem hermenêutica da cultura (GEERTZ, 2012) - sendo neste trabalho interpretado, de um modo geral, como a expressão histórica e cultural de artefatos produzidos e usados por grupos em sociedade (FORTY, 2013; Cardoso, 2013; Meggs, 2010), somado a especificidade de produções realizadas, com apropriações e imaginações vernaculares, por profissionais da área de design.

Assim, o estudo do "artefato do chimarrão", sob a ótica do vernáculo, irá se interessar pela forma de utilização e pelas variações realizadas a partir da experiência da cultura, da memória e do imaginário popular local, por elementos decorativos inseridos com o objetivo de reforçar determinadas identidades de grupos ou indivíduos, e pelo simbolismo associados a essas modificações.

Para a operacionalização desta pesquisa adotamos a abordagem antropo-fenomenológica (DURAND, 2002; BACHELARD, 1993, 2009) com a vertente instauradora da hermenêutica simbólica (RICOEUR, 2009, 2013, 2005; GADAMER, 2011; DURAND, 1996, 1993, 2002), a qual, segundo esses autores, busca a interpretação do mundo, seres e artefatos, através da consciência do pesquisador, formulada com base em sua experiência, utilizando todo o seu "maquinário imaginativo", por não existir corte entre o racional e o imaginário. Em resumo, o método hermenêutico trata de interpretar, analisar, compreender e descrever os fenômenos que se apresentam à percepção e à imaginação. Seu objetivo, neste caso, foi chegar ao conteúdo inteligível e sensível, portanto simbólico, do fenômeno chimarrão.

\section{A história do chimarrão}

Com a intenção de fazer do Paraguai a colônia mais próspera da Espanha, o General Domingo Martínez de Irala, Governador do Rio da Prata, não media esforços para dominar o maior número de terras possível, e foi em uma de suas expedições ao leste, em 1554, que Irala pisa nas terras da Província Del Guairá (atual Estado do Paraná/Brasil).

Ao chegar neste local, depara-se com uma populosa tribo guarani que o recebe com alegria e hospitalidade. Não bastasse tamanha surpresa com a dócil recepção destes índios, ficaram ainda admirados 
com um hábito em especial. Tratava-se da utilização de uma bebida feita com folhas fragmentadas, depositadas em um porongo ${ }^{[2]}$ e sugadas por um canudo de taquara, que recebia um "paciencioso trançado de fibras" (LESSA, 1986), o qual impedia a ingestão de partículas da folha (Figura 2). Os índios, quando questionados sobre a origem de tal bebida, afirmavam que a caá-i (água da erva) era exclusiva para o uso dos pajés, que posteriormente a estenderam para o restante da tribo. Os índios ao ingerirem a bebida sentiam-se mais estimulados, com os corpos e espíritos fortalecidos. No Guairá as folhas de caá (erva mate) eram colhidas facilmente, devido à abundância de árvores no local.

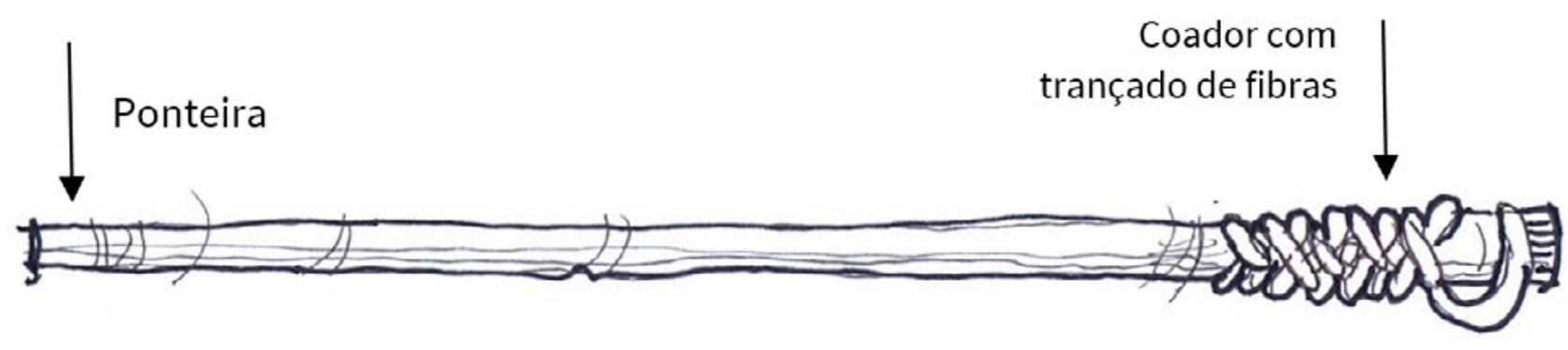

Entusiasmados com os efeitos da bebida, os soldados do General Irala quiseram prová-la. Caindo no gosto destes homens - provavelmente os primeiros estrangeiros a experimentá-la - quando retornam a Assunção fizeram questão de difundi-la das mais diversas formas (LINHARES, 1969). Com essa difusão, se inicia, talvez, uma grande tradição cultural, com o chimarrão sendo a sua manifestação por meio de criações, apropriações e transmissões de um bem simbólico no tempo e no espaço.

O historiador uruguaio Fernando Assunção, em sua obra El Mate, diz que a esta sociedade, juntamente com seu chefe Irala, "es generalmente aceptado que se debe la difusión del mate em las colonias españolas así como sus primeros intentos de explotación, elaboración y comercio" (ASSUNÇÃO, 1967, p.27).

[2] Recipiente geralmente ovóide, fruto das plantas dos gêneros Lagenaria e Cucurbita, depois de seco e desprovido de polpa é usado para esvaziar canoas, beber (cuia) ou transportar líquidos, farinha, etc.

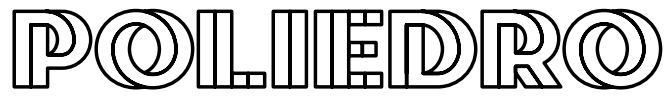


Um século depois, na segunda fase das reduções do Tape, de 1682 a 1801, os jesuítas formam comunidades cristãs com os índios do lugar (atual Estado do Rio Grande do Sul/Brasil). Esses missionários fundam, primeiramente, São Francisco de Borja e São Nicolau, próximas a margem esquerda do Rio Uruguai e após, estabelecem mais cinco reduções que deram início aos Sete Povos das Missões. Segundo Lessa (1986, p.34), "toda a erva colhida no tupambaé era entregue aos curas [padres missioneiros], para que - retida a quantidade necessária para cobrir as despesas do culto - fosse depois distribuída à população". Com o crescimento e cultivo da erva-mate nas reduções estes povos passaram a viver um período de grande opulência, chegando ao ponto de produzirem um tipo único de erva-mate que ficou conhecido por caamini (pura folha), um pó grosso de erva, sem paus, que valia três vezes mais do que a produzida no Paraguai. Segundo Bones da Costa (2004, p.55), "os primeiros ervais foram implantados em 1707, e a primeira colheita se deu dez anos depois". Desta forma, os guaranis aclimataram os ervais naturais dentro das reduções dos Sete Povos das Missões.

Sobre o início da difusão do chimarrão no Rio Grande do Sul, este autor diz que os índios das reduções que saíam em viagem levavam sempre a bomba de tacuapi, a cuia e uma boa provisão de erva-mate, tornando-se assim também grandes promotores dessa divulgação nas nascentes povoações portuguesas de Colônia do Sacramento e São Pedro do Rio Grande (LESSA, 1986, p.35).

Chimarrão (Cimarrón) foi o nome que a infusão recebeu dos colonizadores do Rio da Prata e que depois se difundiu para os demais territórios. A palavra tem origem atribuída ao vocabulário espanhol e português. Para o primeiro, significa "chucro", "bruto", "bárbaro", indicando os animais que se tornaram selvagens. Por analogia, passaram a designar assim a bebida rude e amarga dos nativos, tomada sem a adição de nenhum outro ingrediente que lhe viesse suavizar o sabor. Em português, pode-se atribuir o significado da palavra marron a "clandestino", o que vem ao encontro do significado em castelhano para cimarrón. Em afinidade a este caso, não é difícil perceber a relação entre os primeiros "mateadores" gaúchos e a ilegalidade do uso da erva, uma vez que, no princípio, o comércio da erva-mate era proibido. Esse ser "clandestino" 
é vinculado à palavra gaúcho, palavra adotada para representar o ser primitivo dos pampas da América do Sul, descrito por Bones da Costa (2004) como "aventureiro", "ladrão de gado" e "malfeitor" - homem "sem lei, nem rei", que vivia nos campos desse pampa.

A erva-mate é também conhecida por llex paraguariensis, seu nome científico, que tem classificação atribuída ao botânico e viajante Auguste de Saint-Hilaire (FAGUNDES, 1980, p.26), que por volta de 1820 percorreu as terras do Rio Grande do Sul.

\section{A simbólica do chimarrão (mitos e ritos)}

Se a tradição é uma expressão cultural de um tempo e de um espaço (ARÉVALO, 2004) é porque proclama um mito, um costume, um uso, um imaginário. Talvez, nada possa medir a exata projeção da incidência original do mate. De qualquer forma, examinaremos a expressão recorrente do mito que conta a história da origem do chimarrão. 0 gaúcho, Barbosa Lessa (1986), pesquisador das tradições gaúchas, assim compreende e narra a lenda da origem do chimarrão:

\footnotetext{
$<$ As tribos nômades de outrora derrubavam matos para plantar mandioca e milho até o fim dos recursos de cada terra. Certo dia, um velho índio, já cansado de tantas andanças, preferiu ficar em uma tapera, esperando a morte chegar, e não mais seguir com sua tribo. Este possuía uma filha conhecida por todos como Jary, que por sua vez, não sabia se ficava para fazer companhia a seu pai ou se cumpria sua vontade e seguia adiante com a tribo. Entretanto, apesar de contrariada pelos demais índios, decidiu ficar. A atitude da moça merecia uma recompensa, visto tamanho amor que ela representou ter pelo pai em querer acompanhá-lo. No rancho onde estavam, um dia chegou um pajé desconhecido, que percebendo o que acontecera perguntou à Jary o que ela queria para se sentir feliz: a jovem não pediu nada. Já seu pai, solicitou que o pajé renovasse-lhe as forças a fim de poder seguir com Jary ao encontro da tribo. O pajé lhe entregou uma planta muito verde, perfumada de bondade, e ensinou que ele plantasse, colhesse as folhas, secasse ao fogo, triturasse, botasse pedacinhos num porongo, acrescentasse água quente ou fria e a sorvesse. "Terás nessa nova bebida uma companhia saudável mesmo nas horas tristonhas da mais cruel solidão." Dada a receita, partiu. E dessa maneira surgiu a caá, resultando dela a bebida caá-y chamada posteriormente de chimarrão. Após o velho homem preparar e tomar o caá-y, recuperou as suas forças e seguiu adiante
} 
com a filha, como era seu desejo. Quando encontraram a tribo, todos os receberam com muita alegria e também passaram a beber a infusão da verde erva, amarga e gostosa que prometia aos homens coragem e força, bem como amizade nas horas tristes (LESSA, 1986, p.72).

Além das lendas, são inúmeras as homenagens feitas a este símbolo gaúcho, seja em forma de poema ou de música. É nítido também o que Lessa (1986) comenta em sua obra com respeito à criação de novas amizades a partir do momento de uma "roda de chimarrão", que acima de tudo é um local de "descontração, companheirismo e amizade" (LESSA, 1986, p.67). Este autor indica que o "mateador" encontra, no isolamento de um galpão e no silêncio, as perfeitas condições para trocar confidências com seu outro eu, que se corporifica na cuia.

Os hábitos e a forma de se bebê-lo também se apresentam de maneira distinta em cada região. Na Argentina e Uruguai, na maior parte das vezes, toma-se o chimarrão sozinho, em cuia individual. No sul do Brasil, principalmente no Estado do Rio Grande do Sul, sorve-se em grupo, em cuias médias e grandes, de vários formatos e tamanhos. Com isso, pode-se observar que - em uma mesma região, com formação histórica, econômica e cultural bastante semelhante - se atribui simbolismos e formas de utilização específicas a esta tradição.

Lessa (1986) destaca três elementos como característicos ao gaúcho: o cavalo, o galpão e o chimarrão. Entretanto destes três, afirma que o chimarrão é o mais perene, permanecendo como tradição fundamental do gaúcho. $O$ chimarrão está muito além do seu aspecto físico e de seus benefícios para a saúde. 0 momento de se tomar um chimarrão é praticamente um ritual que se inicia com o preparo dos "avios", ou seja, de seus artefatos, e se estende até a última gota de água da chaleira.

O ritual do preparo do chimarrão começa com o despejo da erva na cuia, de forma que ocupe $2 / 3$ de sua capacidade. Em seguida, tapa-se a boca da cuia com a mão esquerda e, fazendo uma inclinação, joga-se a erva para a outra metade da cuia. Lentamente vai-se trazendo a cuia à verticalidade anterior, de modo tal que o "barranco" de erva não desmorone. Assim, numa metade está a erva, e na outra se irá despejar a água. Desde o princípio, os gestos são lentos e cuidadosos. $O$ "cevador", 
aquela pessoa que prepara o chimarrão, vai também caprichar no "topete" (parte superior) da erva. Depois de mais ou menos cinco minutos a erva já "inchou” o suficiente. Despejada a primeira medida de água na cuia o primeiro chimarrão será do "cevador", que examina se o mesmo está em condições de ser oferecido aos demais (quase sempre, no Rio Grande do Sul, o chimarrão é tomado coletivamente). Primeiro é servido quem está à direita do cevador ou de quem está servindo; e daí segue invariavelmente sendo servido "pela direita" (LESSA, 1968).

Bastam estes tópicos para demonstrar que, sendo o chimarrão uma bebida social, implica todo um ritual e um simbolismo que vão se transmitindo e se transformando através das gerações.

\section{O chimarrão e seus artefatos}

Chamam-se "avios do chimarrão" os artefatos necessários para tomá-lo. Quais são? Os artefatos são fundamentalmente a bomba e a cuia. É claro que outros objetos poderão incorporar os "avios", desde que passem a fazer parte deles (o recipiente para servir a água, o porta-cuia, por exemplo). Para este artigo analisamos apenas a bomba e a cuia.

\section{A bomba de chimarrão}

A bomba de chimarrão é formada, segundo Fagundes (1980), por um canudo metálico, de vinte a vinte e cinco centímetros de comprimento por cinco a oito milímetros de diâmetro, pelo qual é bebido o infuso da erva-mate. Na da ponteira, setor de contato da bomba com a boca do usuário, uma das extremidades é achatada, deixando um pequeno orifício longitudinal para impedir o fluxo excessivo de água. Na outra ponta, possui o ralo, com a finalidade de coar a infusão da erva-mate.

Primitivamente, os índios guaranis criaram a bomba de taquara (Mabea fistulifera), por eles chamada de tacuapi: vocábulo guarani, tacuá (cana oca), api (alisada). A bomba era retirada de um trecho de taquara entre dois nós. Junto ao nó inferior eram feitos pequenos orifícios laterais e brotos eram enrolados ou tramados por cima dos furos, formando assim um coador. No outro lado ficava a ponteira por onde era sorvida a infusão. A criação do tacuapí permitiu que somente o líquido fosse sorvido, sem que houvesse a preocupação de separá-lo das folhas 
ou grão de erva. Em um momento seguinte, aperfeiçoa-se a parte inferior do tacuapí com o trançado de fios ou furos menores para melhorar a filtragem do líquido (Figura 3).

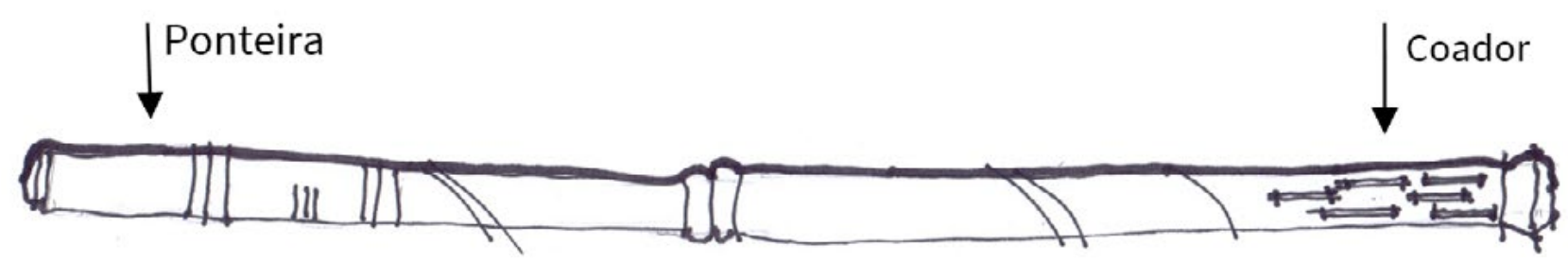

Figura 3 - Tacuapi - bomba de taquara. Elaborado pelos autores.

Depois da bomba primitiva de taquara surgiu a bomba metálica. Isso possibilitou uma evolução formal, de durabilidade, de higiene e de ergonomia. Podemos dizer, por exemplo, que somente com o advento do metal é que realmente foi possível propor um novo design da ponteira.

Fazendo-se um paralelo com os dias de hoje, pode-se notar que a forma de filtragem - que impede a entrada de grãos, evita o entupimento e facilita que a infusão seja sorvida - ainda é um aspecto importante a ser considerado, que pode ser observado pela diversidade de formas de coadores existentes nas bombas atuais, como se verá a seguir. A forma terá, muitas vezes, relação com o tipo de erva que se está utilizando, o tamanho de seus grãos e sua pureza.

Atualmente fazem parte da bomba: a haste (corpo, canudo), a ponteira (bocal, bico, chupeta, boquilha), o coador (bojo, ralo) e o resfriador (anel, passador). A "haste" pode ser lisa, torcida, anelada, reta ou apresentando uma leve curvatura ao aproximar-se da ponteira. A "ponteira" é um bocal onde o mateador apóia seus lábios para beber a infusão, que se inclina até a pessoa que tem a cuia em suas mãos (VILLANUEVA, 1995). Caracteriza-se por ter a extremidade achatada e que em algumas situações pode ser adornada com capa de ouro. 0 "coador" é um ralo perfurado que é colocado na parte inferior da haste e atua como um filtro, impedindo que a erva entre no bulbo (VILLANUEVA, 1995). Suas formas mais comuns são: a de coco (em forma de bola), a de tipo 1001 (pelo 
número de orifícios), a de colher e a de mola (lembra a tacuapi primitiva, apenas recoberta por uma mola). $O$ "resfriador" é o nódulo que enlaça a haste da bomba, próxima do bocal (FAGUNDES, 1980). (Figura 4).

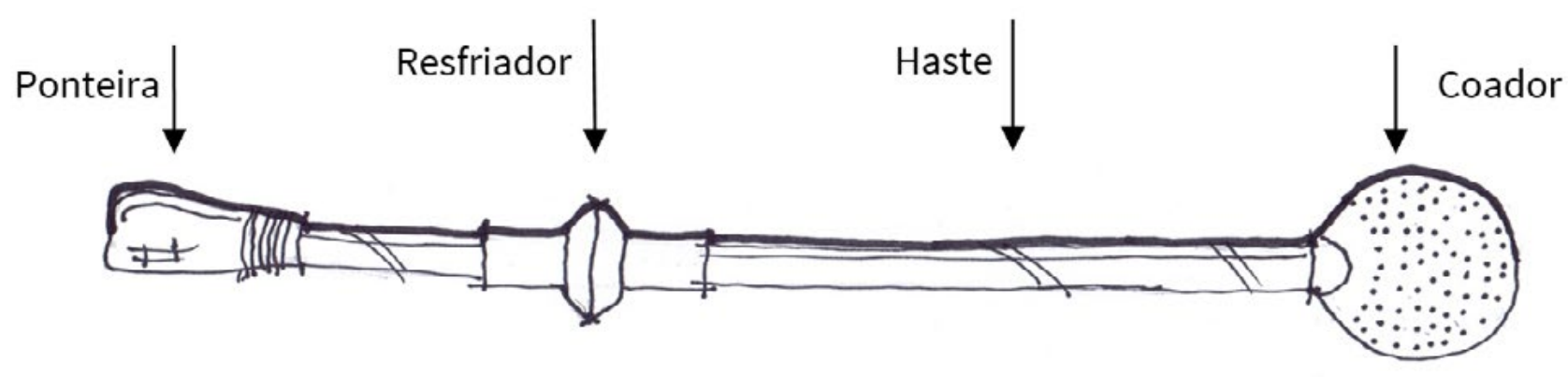

Figura 4 - Bomba de chimarrão. Elaborado pelos autores.

De acordo com Tubino (2011), além da cana do tacuapí (material orgânico pouco usado hoje em dia), os materiais mais encontrados, atualmente, na confecção de bombas são os metálicos: o aço inoxidável, a alpaca, o latão, o ferro e a prata. 0 ouro, em casos especiais, serve de opção apenas aos detalhes, como na ponteira e no resfriador.

o "aço inoxidável", talvez o mais usado atualmente em bombas de chimarrão, é uma liga de ferro e cromo, apresentando propriedades físico-químicas superiores aos aços comuns, sendo a alta resistência à corrosão a sua principal característica (METALOPÉDIA, 2016). Sua resistência à corrosão, as suas propriedades higiênicas e estéticas fazem do aço inoxidável um material muito atrativo, satisfazendo as necessidades de durabilidade, limpeza e aparência à bomba de chimarrão. Tem, em alguns modelos, a possibilidade de abrir-se o ralo para uma higienização mais perfeita (TUBINO, 2011).

A "alpaca" é outra das aplicações importantes para a construção do corpo da bomba de chimarrão; são mais baratas que as de aço inoxidável, mas são menos duráveis e mais frágeis. Conforme a Metalopédia (2016), a alpaca trata-se de uma liga metálica constituída por Cobre, Níquel e Zinco, que também é conhecida por metal branco, por causa do brilho e da coloração semelhantes aos apresentados pela Prata. Utilizada na fabricação 
de bomba de chimarrão devido à sua composição que confere resistência à corrosão e por ser uma alternativa mais econômica. É ainda uma liga dúctil e maleável. Como bomba de chimarrão a alpaca "possui boa duração e não apresenta dificuldades de manutenção" (TUBINO, 2011. p.11). Com cuidados corretos no uso e na higiene, pode durar até dez anos.

O "latão" é um dos metais utilizados para compor o corpo de bombas de chimarrão. 0 inconveniente é que, segundo Tubino (2011), por ser um metal de baixa durabilidade que tende a descascar após cerca de dois meses, pode interferir no sabor do mate. De acordo com a Metalopédia (2016), o latão é uma liga metálica constituída por Cobre e Zinco. As percentagens de Zinco na liga variam entre 3 a 45\%. Esta liga é utilizada para fabricar objetos decorativos, dada a sua aparência brilhante que se assemelha ao Ouro. Uma das principais características do latão é ser altamente maleável tendo um ponto de fusão relativamente baixo e as suas características em escoamento fazem do latão um material de fácil fundição. Em síntese é uma bomba com um material de pouca durabilidade e de difícil manutenção.

As bombas de chimarrão de "ferro" duram um pouco mais do que as de latão, profere Tubino (2011). Alerta que deve-se evitar o uso da bomba quando o metal começa a ganhar um aspecto escurecido. Elemento químico com símbolo Fe, o Ferro encontra-se no estado sólido à temperatura ambiente, sendo extraído da natureza sob a forma de minério de Ferro. Dá origem a várias formas de aço após adição de Carbono e é reciclável (METALOPÉDIA, 2016). Para a bomba de chimarrão, é de difícil manutenção, "ficando - após algum tempo de uso - com a cor acinzentada/escura" (TUBINO, 2011, p.31).

A bomba de chimarrão de "prata" foi, nos primórdios, uma imitação da bomba tacuapí primitiva. Segundo Villaneuva (1995, p.125), "de plata se hicieran las primeras bombillas metálicas". Este autor diz que primitivamente a indústria dos metais se singularizou entre nós com as produções de prata. Tubino (2011) descreve que as bombas de prata são mais requintadas, duráveis, especialmente as mais puras (o grau máximo de pureza da prata é indicado pelo número 900). Geralmente, têm detalhes como ponteira e resfriador em ouro. A prata ou argento (do latim vulgar argentum) à temperatura ambiente encontra-se no estado sólido. 
A bomba de prata, por ter um custo financeiro maior, leva consigo um valor simbólico hierárquico também mais elevado. Segundo Ricca (2009, p.112), "desde o século XVI este material se impôs frente aos outros devido a abundância, maleabilidade e resistência, acentuada pela combinação com outros metais". Desde o passado muitas vezes esse tipo de bomba foi minuciosamente ornamentado com anéis e virolas, com motivos do campo e detalhes de aves ou plantas - além de estrias e espirais.

Finalizamos aqui a análise sobre as bombas de chimarrão, comentando sobre sua medida mais ergonômica e alguns subsídios curiosos. A indicação básica em relação à medida adequada da bomba é a de que deve possuir, mais ou menos, o dobro da altura da cuia, ou seja, que metade fique para fora da cuia. Uma bomba muito pequena ou grande demais torna a ação de matear inadequada. Por outro lado, recentemente, devido ao surgimento de ervas extremamente finas, foram criados filtros de tecido ("camisinhas" do mate), que servem para envolver o coador, impedindo o entupimento do chimarrão. Outra informação curiosa e atual é que existem na Argentina alguns mates econômicos e descartáveis que incluem bombas de plástico, as quais, porém são rechaçadas por consumidores mais ortodoxos.

\section{A cuia de chimarrão}

A cuia de chimarrão é confeccionada, conforme Fagundes (1980), de porongo (Lagenaria vulgaris), fruto do porongueiro, trepadeira rasteira com folhas largas, encontrado no sul da América do Sul. O porongo, depois de maduro, se torna oco, portanto sendo passível de tornar-se uma vasilha para líquidos. Os porongos são chamados em guarani de yeruá. A cuia é chamada de caiguá: caa (erva), i (água) e guá (recipiente). Literalmente: recipiente para a água da erva-mate. Em relação às cuias originais, pode-se observar que pouco mudou em relação e a sua forma. A origem da cuia vem, provavelmente, da necessidade de artefatos que contivessem líquidos quentes, e que permitissem seu manuseio sem que o calor chegasse às mãos de quem o carregava. Dos materiais utilizados pelos indígenas, o que apresentou melhor funcionalidade foi o porongo cortado, utilizado até hoje. A cuia de porongo necessita de algumas etapas em sua confecção - que vão desde a forma de colheita, 
corte do porongo até a cura final - para que possa ser utilizada sem que o sabor do chimarrão se altere, conforme é descrita por vários autores (LESSA, 1986; FAGUNDES, 1980).

Em alguns casos, existem trabalhos decorativos e simbólicos nas cuias. Os desenhos são sempre inspirados na natureza, pontificando os motivos florais, do campo, puros ou estilizados. Os bocais de alpaca são muito comuns, assim como os de prata. Além disso, a partir do século $\mathrm{XVIII,} \mathrm{a} \mathrm{influência} \mathrm{da} \mathrm{prataria} \mathrm{religiosa,} \mathrm{principalmente} \mathrm{a} \mathrm{de} \mathrm{origem} \mathrm{por-}$ tuguesa, se fez sentir em nossos costumes gaúchos, pois a matéria-prima existia em abundância. Os artesãos da época adaptavam sua arte religiosa aos utensílios gaúchos. Surgem então os mates-de-cálice ou mates-de-pé, usando vários tipos de metal (ASSUNÇÃO, 1967). As formas e a ornamentação dos artefatos do chimarrão mudam conforme a região de uso. Os artesãos da prata e do metal em geral seguiram influências dos estilos de cada época. As obras do século XVIII são de estilo barroco e rococó; mais tarde incorporam decorações e simbolismos românticos e a cuia de prata se converte em um objeto de adorno a partir do final do século XIX (DE LE COMTE, 2005).

Além das cuias naturais (extraídas da natureza: porongo, cana, marfim, guampa, coco), temos à venda cuias compostas artesanalmente ou industrialmente de vários materiais, dos quais os mais comuns são: prata, madeira, madeira forrada com alumínio, porcelana, porcelana esmaltada, vidro, louça, plástico. Apesar de todas essas alternativas, a cuia de porongo segue tendo uma maior aceitação. De acordo com Fagundes (1980), quanto à forma temos a cuia gajeta ou galleta (bolacha em espanhol), a cuia pêra, a cuia teto-de-vaca, a cuia coquinho, a cuia torpedo, a cuia saco-de-touro e a cuia pescoço. (Figura 5).
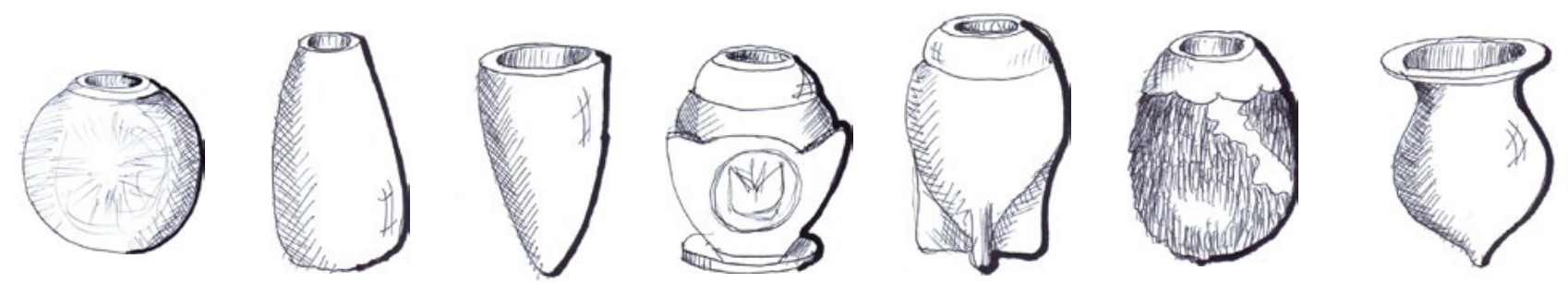

Figura 5 - Formatos de cuia. Da esquerda para a direita: Gajeta, Pêra, Teto-de-vaca, Coquinho, Torpedo, Saco-de-touro e Pescoço. Elaborado pelos autores.

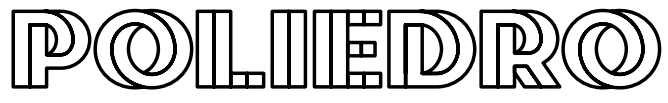


A gajeta, produzida com o porongo grosso, é executada basicamente para quem consome o chimarrão individualmente. Por ser bastante curta, a gajeta tem a vantagem de possibilitar o consumo rápido e antes que a água esfrie. A gajeta tem um manuseio muito prático. O formato de cuia coquinho é o tradicionalmente utilizado pelo gaúcho solitário do campo. Destaca-se, também, por ser mais popular entre os mais jovens. O tamanho do bocal de inox varia de acordo com a região. No Uruguai, por exemplo, é bastante discreto. Na Argentina o detalhe ganha contornos mais chamativos. Já a torpedo não possui muitas diferenças quando comparada com a do tipo coquinho. O grande avanço dela é não necessitar de suporte móvel. O formato quadricular da base permite o apoio sem quaisquer riscos de queda.

O que vem sendo dito nessa parte do texto deixa claro como as cuias vão sendo criadas e alteradas de forma espontânea, atendendo às necessidades de seus utilizadores e incorporando melhorias a partir de experimentações que se dão ao longo de gerações e a partir das possibilidades que o meio oferece para sua transformação. É possível perceber desta forma, a origem vernácula dos avios do chimarrão, que ao longo do tempo irá incorporar novos elementos e assumir novas funções simbólicas.

\section{Chimarrão: uma cultura mutante}

Como vimos, a evolução dos equipamentos e a tecnologia associada a eles é outro fator que vem acrescentar no universo do chimarrão. Um exemplo são as bombas com diferentes tipos de coadores, específicos para cada tipo de erva, desmontáveis para limpeza, elaborada em aço inox ou outro material resistente à temperatura e à ferrugem. As cuias por sua vez, evoluíram especialmente no que diz respeito aos materiais. Mesmo com a diversidade de formas de cuias elaboradas a partir de porongo, foi com utilização de novos materiais que as cuias apresentaram maior diferenciação. Às tradicionais cuias de porongo revestidas ou não e de louça, surgem as cuias feitas de vidro, alumínio colorido, plástico ou silicone. As chaleiras veem-se substituídas por jarras elétricas, algumas com marcação de temperatura própria para o consumo do chimarrão. E em um último estágio de incorporação do hábito pela cultura de massa e industrialização, surgem filtros de pano chamado "camisinha" que se sobrepõem ao coador 
da bomba para uma melhor filtragem e também os "mates" descartáveis, prontos para beber e serem jogados fora após o consumo.

Este panorama, que abrange questões históricas, culturais, simbólicas, econômicas e sociais demonstra a amplitude que essa cultura mutante do chimarrão abarca. Constitui-se um universo diverso e rico, em que, por meio de uma bebida, indivíduos e grupos podem expressar sua identidade, seja por tomar o chimarrão e explicitamente ou implicitamente declarar sua raiz gaúcha e platina, seja pela personalização dos equipamentos que utiliza para tomá-lo, inclusive gravando seus nomes nos artefatos. Coube-nos, sob a ótica do design vernacular, a partir da observação e pesquisa dos equipamentos, evidenciar essa riqueza e apresentar a diversidade de forma sistemática, analisando as mudanças e as características explícitas e implícitas a estes artefatos.

\section{Considerações finais}

O chimarrão é essa grande instituição material e simbólica do sul do continente que nada fala e tudo diz. É esse milagre que não se agradece ${ }^{[3]} \mathrm{e}$ se toma em parceria. É um lugar de memória que cria comunhão e identidade, sempre em trânsito: com novas formas e "enfeites" de cuias e bombas. Hoje temos, paradoxalmente, o chimarrão ancestral em bomba tacuapí convivendo com cuias de plástico. $\mathrm{E}$ foi isso que nos interessou examinar: essas evoluções com rupturas simbólicas e técnicas. Interessou-nos e foi, acreditamos, uma pesquisa original para os campos do imaginário e do design vernacular gaúcho. 0 design vernacular, em relação ao tema desta pesquisa, foi tido como uma expressão histórica e cultural de artefatos produzidos e usados por grupos em sociedade.

Para a compreensão dessas evoluções e rupturas foi necessário estarmos na experiência do fenômeno, como "mateadores". Mas mais do que isso tivemos que mergulhar na história do chimarrão, procurando entender seu imaginário, sua materialidade e sua arquetipologia: a força da ideia guarani - do porongo cru e do tacuapí e suas variações no tempo e espaço. Com isso tentamos compreender a dinâmica da cultura do uso, dos mitos e dos ritos em relação a esses artefatos. Através de uma hermenêutica simbólica e compreensiva analisamos seus aspectos técnicos e estéticos.

[3] Agradece-se somente quando se vai sair da roda de chimarrão. Regra que faz parte desse costume.

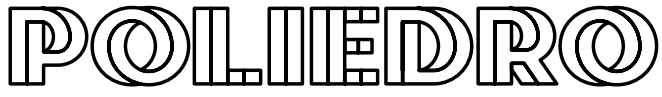


Chegamos à conclusão que os grupos e as segmentações de uso, em um tempo histórico, sempre interpretam e reelaboram aquilo que neste campo lhes é oferecido, transformando esses artefatos em elementos heterogêneos. Ou seja, tentamos compreender e apreender a dinâmica de um processo complexo (uma multidimensionalidade da experiência da "roda-de-chimarrão" e seus artefatos) no qual todos os atores transformam e são transformados, no dinamismo mútuo das ações e das representações, contribuindo, através de motivações simbólicas e imaginárias, para essas mudanças.

Finalmente, desejamos que neste campo de investigação, novas interpretações surjam, pois o tema precisa ser mais desenvolvido na pesquisa técnica, do imaginário, do design vernacular e da antropologia simbólica, de modo que nos permitam entender esse contexto cultural de uma forma mais ampla, dentro do qual os usuários do chimarrão constroem e reformulam suas representações e suas práticas. Temos a consciência de que não foi possível mapear todas as alternativas de configuração deste campo. $O$ resultado foi apenas uma síntese de aproximações sucessivas da "nossa verdade" sobre o assunto: um ponto-de-vista "criando" um objeto.

\section{Referências}

\section{ARÉVALO, J. M. La tradición, el patrimonio y la identidad.}

Revista de estudios extremeños. Volume 60, número

3. Espanha: Editora da Diputación de Badajoz, 2004.

ASSUNÇÃO, Fernando O. El mate. Motevideo: Arca, 1967.

BACHELARD, Gaston. A poética do devaneio.

São Paulo: Martins Fontes, 2009.

O novo espírito científico. Lisboa: Edições 70, 2008.

A poética do espaço. São Paulo: Martins Fontes, 1993. 
BONES DA COSTA, Elmar. História ilustrada do Rio

Grande do Sul. Porto Alegre: RBS Publicações, 2004.

CARDOSO, Rafael. Design para um mundo

complexo. São Paulo: Cosac Naify, 2013.

DURAND, Gilbert. A imaginação Simbólica. Lisboa: Edições 70, 1993.

As estruturas antropológicas do imaginário:

introdução à arquetipologia geral. Martins Fontes, 2002.

. Campos do imaginário. Lisboa: Instituto Piaget, 1996.

DURHAM, Eunice R. A dinâmica da cultura: ensaios

de antropologia. São Paulo: Cosac Naify, 2004.

FAGUNDES, Glênio Cabral Portela. Cevando

mate. Porto Alegre: Habitasul, 1980.

FINIZOLA, F. Tipografia vernacular urbana: uma análise dos letreiramentos populares. São Paulo: Blucher. 2010.

FORTY, Adrian. Objeto de desejo: design e sociedade

desde 1750, São Paulo: Cosac Naify, 2013.

GADAMER, Hans-Georg. Verdade e método. Petrópolis, RJ: Vozes, 2011.

GEERTZ, Clifford. A interpretação das

culturas. Rio de Janeiro, LTC, 2012.

HOBSBAWN, Eric. A invenção das tradições.

São Paulo: Paz e Terra, 2015.

LESSA, Luiz Carlos Barbosa. História do

Chimarrão. Porto Alegre: Sulina, 1986. 
LINHARES, Temístocles. História econômica do

mate. Rio de Janeiro: José Olympio, 1969.

MEGGS, Philip. História do design gráfico.

São Paulo: Cosac \& Naify, 2010.

METALOPÉDIA; Metalurgia. Ligas Metálicas. Metais. "Aço Inoxidável". "Alpaca". "Latão". "Ferro". Disponível em <https:// sites.google.com/a/catim.pt/metalopedia/metalurgia/ligasmetalicas/aco-inoxid.htm>. Acesso em 02 de dezembro de 2016.

RAMIL, Vitor. Chimarrão. In: Délibáb. Rio de Janeiro: Cia dos Técnicos, 2008. 1 CD.

RICCA, Javier. El Mate. Buenos Aires: Sudamericana, 2009.

RICOEUR, Paul. A Metáfora Viva. São Paulo: Edições Loyola, 2005. Hermenêutica e Ideologias. Petrópolis: Vozes, 2013. Teoria da Interpretação. Lisboa: Edições 70, 2009.

SAINT-HILAIRE, Auguste. Viagem ao Rio Grande do

Sul, 1820-1821. Belo Horizonte: Itatiaia, 1999.

. Viagem ao Rio Grande do Sul. Tradução de Adroaldo Mesquita da Costa. Brasília: Conselho Editorial do Senado Federal, 2002. Disponível em <http://www2.senado.gov.br/bdsf/ bitstream/id/1064/4/626704.pdf>. Acesso em 15 fev. 2013.

TUBINO, Wilson. Os mistérios ocultos do chimarrão: aspectos místicos da erva-mate. Porto Alegre: Evangraf, 2001.

VILLANUEVA, Amaro. El Mate. Buenos Aires: Nuevo Siglo, 1995.

WUNENBURGER, Jean-Jacques. O imaginário. São Paulo: Loyola, 2007 